Geschäftsstelle des Bundesverbandes

DOI 10.1007s00292-013-1738-5

๑) Springer-Verlag Berlin Heidelberg 2013

\section{Deutscher Pathologen e.V.}

Invalidenstraße 90, 10115 Berlin

Tel. +49(0)030/3088197-0

E-Mail: bv@pathologie.de

\title{
Pathologie - Für das Leben und seine Qualität
}

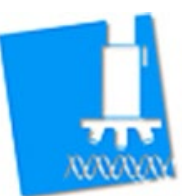

BUNDESVERBAND DEUTSCHER

PATHOLOGEN E.V.

\begin{abstract}
Wer sind die Pathologen, was tun sie und was fordern sie? Die neue politische Kurzinformation für in der Gesundheitspolitik Tätige über das Fachgebiet und den Bundesverband Deutscher Pathologen e.V. liegt vor. Erhältlich ist die Broschüre digital auf www.pathologie.de oder als Print anzufordern über bv@pathologie.de.
\end{abstract}

Auszug:

Der Bundesverband Deutscher Pathologen ist der Zusammenschluss aller berufstätigen Pathologen in Universität, Krankenhaus und Praxis. Auch die Weiterzubildenden sind hier organisiert. Der Verband sieht sich als "die Kammer des Fachgebiets“. Sein Ziel ist es, die Mitglieder in die Lage zu versetzen, den Beruf in der bestmöglichen Weise auszuführen.

Der Verband fördert und fordert seine Mitglieder bei schwierigen und finanziell aufwendigen Umstrukturierungen des Fachgebietes. Dazu gehörte innerhalb der letzten 15 Jahre der Aufbau einer flächendeckenden und qualitativ hochwertigen Molekularpathologie als Schlüssel für die zukünftige Versorgung von Patienten in der individualisierten Medizin.

Ein koordiniertes System von fachlichen Definitionen, Bildungsangeboten und der Entwicklung von Kooperationsmustern sowie politischen Hilfen bei der Umsetzung hat $\mathrm{zu}$ einem bundesweiten Angebot dieser speziellen Kompetenzen geführt. Der Sachverstand ist dort, wo er gebraucht wird: in den Tumorzentren, im Team der Fachärzte an der Seite der Patienten.

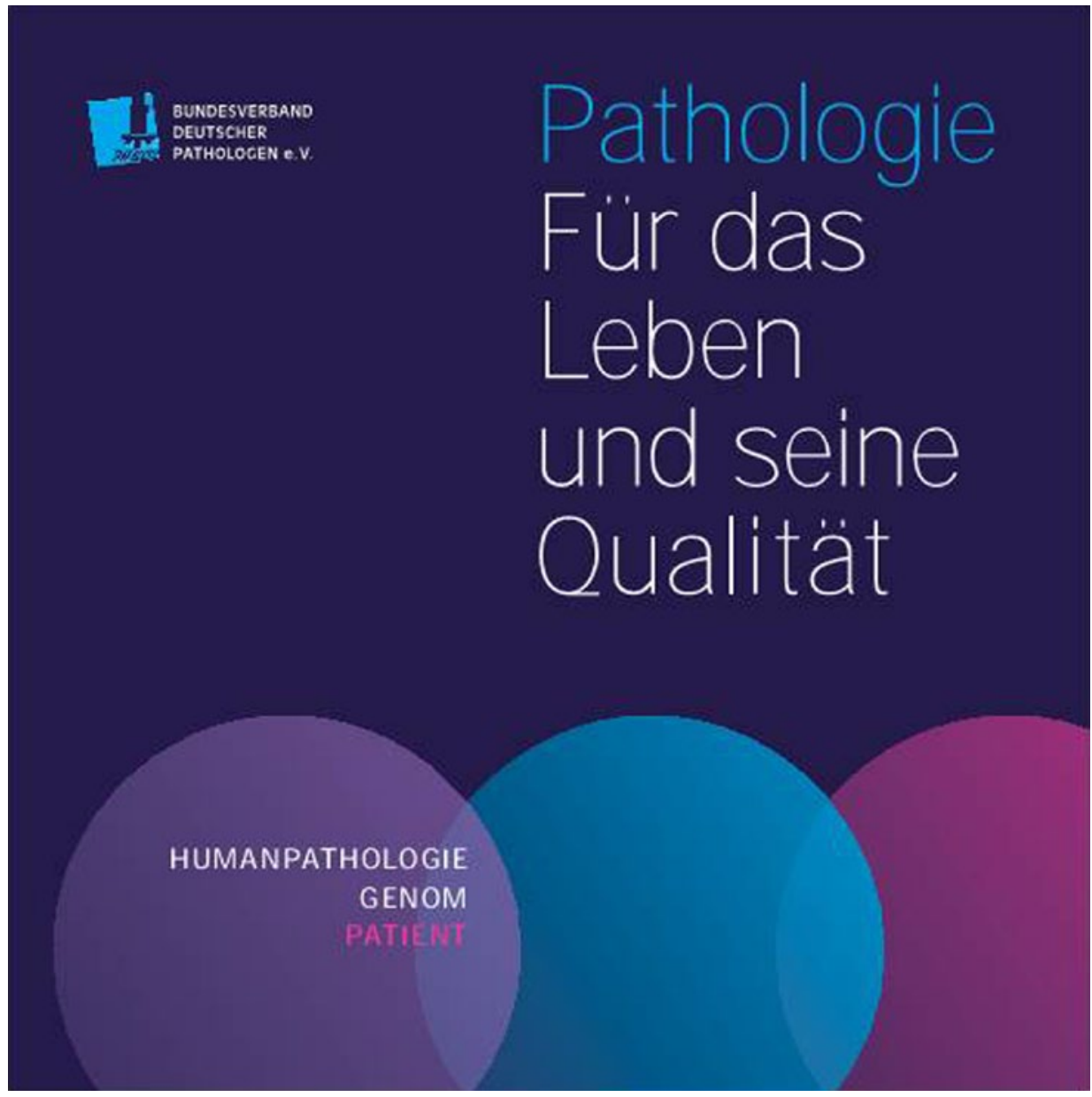

Erhältlich ist die Broschüre digital auf www.pathologie.de oder als Print anzufordern über bv@pathologie.de. 